\title{
Direct Clinical Health Effects of the Consumption of Alcohol Mixed With Energy Drink in Dutch Adolescents
}

\author{
Karin Nienhuis ${ }^{a}$, Joris J. Van Hoof ${ }^{b}$, and Nicolaas Van der Lely ${ }^{a}$

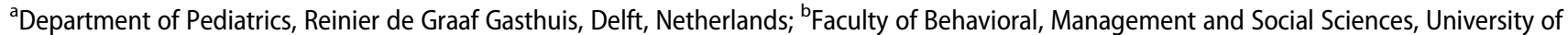 \\ Twente, Enschede, Netherlands
}

\begin{abstract}
The direct clinical health effects of alcohol mixed with energy drinks (AmED) consumption are largely unknown. Using data from a nationwide questionnaire, two groups were compared: adolescents who consumed an energy drink at the event (ED+) and adolescents who did not (ED-). Blood alcohol concentration (BAC), duration of loss of consciousness, mean age, sex ratio, and habitual characteristics did not differ between the groups. In the ED+ group, more adolescents had lower education and drugs were used twice as often. Consumption of AmED with relatively low doses of caffeine does not lead to higher BAC in Dutch adolescents presenting to the hospital with alcohol intoxication.
\end{abstract}

\section{KEYWORDS}

adolescents; alcohol intoxication; alcohol mixed with energy drink; direct clinical health effects

\section{Introduction}

In the past decade, the number of adolescents treated in the department of pediatrics for alcohol-related problems in the Netherlands has risen. Most of these adolescents were admitted to the hospital because of reduced consciousness due to binge drinking ( $\geq 4$ or $\geq 5$ alcoholic beverages in a few hours for girls and boys, respectively; Van der Lely, 2016; Van der Lely, Schreurs, Van Hoof, \& Van Dalen, 2016). Parallel to this development, an increase in the consumption of energy drinks in Europe and the United States has been seen among youngsters. Energy drinks were first sold in 1987 by Red Bull ${ }^{\circledR}$ in Austria, and their popularity in Europe and the rest of the world has been rising ever since (Red Bull, 2017; Reissig, Strain, \& Griffiths, 2009; ). In the United States, the number of visits to the emergency department involving energy drinks doubled between 2007 and 2011 (Mattson, 2013). The consumption of alcohol mixed with energy drinks (AmED) is gaining popularity as well (O’Brien, McCoy, Rhodes, Wagoner, \& Wolfson, 2008), although the consumption of AmED in the Netherlands has declined during recent years (Van Dorsselaer et al., 2016). Adolescent AmED consumption has various negative consequences: adolescents consuming AmED are heavier drinkers (Rossheim et al., 2016; Verster, Benson, Johnson, Scholey, \& Alford, 2015), show risk-taking behavior (O'Brien et al., 2008), have a greater motivation to drink alcohol (Marczinski, Fillmore, Henges, Ramsey,
\& Young, 2013), and have greater odds of alcohol dependence and greater hazardous drinking (Skewes, Decou, \& Gonzales, 2013; Verster et al., 2015). Furthermore, adolescent AmED consumption has negative effects on brain development (Díaz et al., 2016). Despite the extensive research that has been previously conducted, the direct clinical health effects of AmED consumption are largely unknown. Therefore, the aim of this study was to examine these direct clinical health effects in adolescents who presented to the pediatrics department with alcoholrelated problems.

Adolescent alcohol consumption, and especially irresponsible consumption, leads to health damage in both the short and long term. Short-term complications of alcohol intoxication are reduced consciousness, hypothermia, electrolyte disturbances, hypoglycemia, and metabolic acidosis. However, these complications appear to be mild in youngsters (Bouthoorn, Van der Ploeg, Van Erkel, \& Van der Lely, 2011). Nonmedical complications of alcohol intoxication in adolescents include accidents, injuries, violence, and risk-taking sexual behavior (Bonomo et al., 2001). Alcohol consumption in adolescents (ages 10 to 24 years) is the main risk factor contributing to disability-adjusted life-years (Gore et al., 2011).

Long-term effects of adolescent alcohol consumption are increased risk of developing cancer (Corrao, Bagnardi, Zambon, \& La Vecchia, 2004), alcohol-related problems later in life (i.e., problematic alcohol use; Gross 
et al., 2016) and, most importantly in adolescence, brain damage (Guerri \& Pascual, 2010). During adolescence, maturation of the brain occurs, mostly by forming new connections, as well as by forming more stable connections within the brain. Drinking alcohol during adolescence harms this maturation (i.e., smaller hippocampal volume and abnormalities in the prefrontal cortex), leading to lifelong impairments, including memory dysfunction (Guerri \& Pascual, 2010).

Not only does alcohol lead to negative health consequences in adolescents but energy drinks may cause health consequences as well (Koivusilta, Kuoppamäki, \& Rimpelä, 2016; Kristjansson, Sigfusdottir, Mann, \& James, 2014). In children who consume energy drinks, there is a relation between complaints (headaches, stomachaches, sleeping problems, and low appetite) and quantity of caffeine consumed (Kristjansson et al., 2014; Koivusilta et al., 2016; Seifert, Schaechter, Hershorin, \& Lipshultz, 2011). There is a dose-response relationship between the consumption of energy drinks in young adolescents and a late bedtime (Koivusilta et al., 2016). Furthermore, energy drink consumption is positively correlated with hazardous alcohol consumption and alcohol dependence (Arria et al., 2011; Emond, GilbertDiamond, Tanski, \& Sargent, 2014; Magnezi, Bergman, Grinvald-Fogel, \& Cohen, 2015). Adolescents who consume energy drinks tend to be heavier drinkers and tend to drink more alcohol later in life than adolescents who do not consume energy drinks (Miyake \& Marmorstein, 2015; Patrick, Evans-Polce, \& Maggs, 2014).

Although energy drinks have been on the market since 1987, the negative consequences of AmED were not reported until the late 1990s (Ferreira et al., 2004; Red Bull, 2017; Riesselmann, Rosenbaum, \& Schneider, 1998;). Adolescents consume AmED for various reasons: because they like the taste, to feel intoxicated, to feel awake, out of curiosity, to consume more alcohol, to reduce the side effects of alcohol, for social reasons, and to hide the flavor of alcohol (Bonar et al., 2015; Magnezi et al., 2015). AmED consumers seem to be heavier drinkers than non-AmED consumers (Rossheim et al., 2016; Verster et al., 2015). Consumption of AmED in adolescents is associated with risk-taking behaviors: sexual risks, injury, need for medical treatment (O'Brien et al., 2008; Roemer \& Stockwell, 2017), driving with too high blood alcohol concentration (BAC), and riding with an intoxicated driver (Roemer \& Stockwell, 2017; Woolsey et al., 2015). It is also associated with greater odds of warnings, tickets and motor vehicle accidents, drug use, and smoking (Martz, Patrick, \& Schulenberg, 2015; Trapp et al., 2014). Furthermore, AmED consumption may lead to greater motivation to consume alcohol (Marczinski et al., 2013). Direct clinical health effects, such as the relation between AmED consumption and BAC, have rarely been examined, and only a small case series has been published (Cleary, Levine, \& Hoffman, 2012).

Long-term consequences of AmED consumption include negative consequences of alcohol consumption, symptoms of alcohol dependence, and greater hazardous drinking (Skewes et al., 2013; Verster et al., 2015). In adolescence, AmED consumption has negative effects on brain development. It leads to neuronal death and damage to the lipids and proteins in the hippocampus and temporal cortex (Díaz et al., 2016). Since 2010, premixed AmED products are no longer available in the United States due to pressure from the Food and Drug Administration (FDA) on the manufacturers of these beverages. The FDA concluded that there is no support for the claim that the addition of caffeine to alcoholic beverages is "generally recognized as safe" (U.S. Food and Drug Administration, 2010). However, consumption of AmED is inevitable because adolescents started mixing energy drinks with alcohol themselves (Martz et al., 2015).

Alcohol consumption and energy drink consumption have both long-term and short-term negative effects on adolescents. It is thought that the combination (AmED) might be even worse. The negative effects of AmED are known, but these effects are either consequences of the result of AmED consumption (i.e., injuries as a result of risk-taking behavior) or long-term effects (i.e., alcohol dependence later in life). The direct clinical health effects or consequences of AmED consumption are largely unknown. Therefore, in this study, the relation between AmED consumption and BAC is examined in adolescents presenting to the pediatric department. Our hypothesis was that BAC is higher in adolescents who consume AmED because they tend to drink more and longer and have greater motivation to drink alcohol.

\section{Method}

\section{Data collection}

Data were collected using the Dutch Pediatric Surveillance System (NSCK) from January 1, 2014, to December 31, 2016. Every time an adolescent is admitted to the department of pediatrics with a problem related to the consumption of alcohol, the admission is reported to the NSCK by the pediatric team. The next morning, the pediatrician interviews the adolescent and his or her parents about the drinking episode leading up to the hospital treatment, drinking patterns, psychosocial problems, sexual problems, and medication and drug use. This information is used to complete a questionnaire, which is sent to the NSCK. 
Accordingly, all adolescents ages $<18$ years with a BAC of $>0 \mathrm{~g} / \mathrm{L}$ are included in the surveillance system, which has existed since 2006.

Additional information collected through the questionnaire includes general and demographic information, medical information about intoxication, and treatment characteristics and hospital information. Beginning in 2014, a new questionnaire was used, in which a question about the co-use of energy drinks was added. The consumption of energy drinks was the grouping variable. Other variables of interest in this study were BAC $(\mathrm{g} / \mathrm{L})$, gender, age at admission to the hospital, education level, ethnicity, duration of reduced consciousness, hospital stay, part of the day at admission, drug use, age of consuming first alcoholic beverage, smoking, and alcohol consumption during the weekend.

\section{Participants}

Inclusion criteria for the current study were as follows:

- adolescents $<18$ years of age;

- admission to the hospital with BAC $>0.0 \mathrm{~g} / \mathrm{L}$;

- reduced consciousness (other atypical causes for hospital treatment, such as trauma or suicide, were excluded from the current analyses);

- registration if an energy drink was consumed (yes/ no).

In total, 2,257 questionnaires were received. The use of energy drinks was known in 615 patients. Of them, 523 matched the inclusion criteria and were included. A total of 48 adolescents (9.2\%) consumed energy drinks in combination with large quantities of alcohol, and 475 adolescents (90.8\%) did not.

\section{Statistical analysis}

The data were analyzed using IBM SPSS Statistics for Windows, version 21 . The normality of continuous data was checked using the Shapiro-Wilk test. All continuous data were distributed non-normally, so Mann-Whitney $\mathrm{U}$ tests were performed to compare these data. The chisquare test was used for the examination of the relations between the nominal variables. $P$-values less than .05 were considered statistically significant.

\section{Baseline characteristics}

Two groups were created: adolescents who did (ED+; $N=48,9.2 \%)$ and adolescents who did not (ED-; $N=475,90.8 \%)$ consume energy drinks mixed with alcohol or in addition to the consumption of alcohol before hospitalization. The ratios of boys and girls were comparable in both groups (Table $1 ; \chi^{2}(1, N=519)=$
Table 1. Baseline Characteristics.

\begin{tabular}{|c|c|c|c|c|}
\hline & $\begin{array}{c}E D+ \\
(N=48) \\
(S D)\end{array}$ & $\begin{array}{c}\text { ED- } \\
(N=475) \\
(S D)\end{array}$ & $\begin{array}{c}\text { Total } \\
(N=523) \\
(S D)\end{array}$ & $p$-value \\
\hline Gender (\%) & & & & $.199^{\mathrm{a}}$ \\
\hline Male & 60.9 & 51.0 & 52.0 & \\
\hline Female & 39.1 & 49.0 & 48.0 & \\
\hline $\begin{array}{l}\text { Mean age at admission } \\
\text { (years) }\end{array}$ & $\begin{array}{l}15.56 \\
(1.109)\end{array}$ & $\begin{array}{l}15.42 \\
(1.159)\end{array}$ & $\begin{array}{l}15.43 \\
(1.154)\end{array}$ & $.413^{\mathrm{b}}$ \\
\hline
\end{tabular}

${ }^{\mathrm{a} C h i-s q u a r e ~ t e s t ; ~}{ }^{\mathrm{b}}$ Mann-Whitney U test.

$1.652, p=.199)$. The mean age during admission did not differ significantly between the groups (Table $1 ; u=$ 10586.0, $z=-0.819, p=.413$ ).

\section{Results}

\section{Background characteristics}

Education levels were divided into three categories: low (VMBO/pre-vocational secondary school), middle-high (HAVO/senior secondary education), and high (VWO/ university preparatory education). A significant difference between the groups was found $\left(\chi^{2}(2, N=387)=\right.$ $6.370, p=.041)$ : significantly more adolescents had lower education in the ED+ group than in the EDgroup (Table 2). There were more adolescents with a non-Dutch nationality in the ED+ group than in the ED- group (21.3\% versus $10.7 \%$, respectively; Table 2), and this difference was significant $\left(\chi^{2}(1, N=496)=\right.$ $4.617, p=.032)$.

\section{Intoxication and treatment characteristics}

In this study, no significant difference in BAC between the groups was observed (Table 3; $u=10481.5, z=$ $-0.921, p=.357)$. Adolescents who consumed energy drinks used drugs at the time of admission almost twice as often (19.1\% versus $10.0 \%)$. This difference was marginally significant (Table $3 ; \chi^{2}(1, N=505)=3.641, p=$ .056). Hospital stay $(u=7415.0, z=-1.326, p=0.185)$, duration of reduced consciousness $(u=3587.5$, $z=-0.916, p=.360)$, and part of the day of admission

Table 2. Background Characteristics.

\begin{tabular}{lcccc}
\hline & $\begin{array}{c}\text { ED+ } \\
(N=48)\end{array}$ & $\begin{array}{c}\text { ED- } \\
(N=475)\end{array}$ & $\begin{array}{c}\text { Total } \\
(N=523)\end{array}$ & $p$-value \\
\hline Education level (\%) & & & & $.041^{* a}$ \\
$\quad$ Low & 65.7 & 43.5 & 45.5 & \\
$\quad$ Middle-high & 17.1 & 29.5 & 28.4 & \\
$\quad$ High & 17.1 & 27.0 & 26.1 & $.032^{* a}$ \\
Ethnicity (\%) & & & & \\
$\quad$ Dutch & 78.7 & 89.3 & 88.3 & \\
$\quad$ Non-Dutch & 21.3 & 10.7 & 11.7 & \\
\hline
\end{tabular}

${ }^{a}$ Chi-square test.

$"=P$-value. 
Table 3. Hospitalization Characteristics.

\begin{tabular}{|c|c|c|c|c|}
\hline & $\mathrm{ED}+(N=48)(S D)$ & $\mathrm{ED}-(N=475)(S D)$ & Total $(N=523)$ & $p$-value \\
\hline BAC (\%, whole blood) & $0.199(0.478)$ & $0.197(0.511)$ & $0.197(0.508)$ & $.357^{\mathrm{a}}$ \\
\hline Duration of reduced consciousness (hours) & $2.74(2.044)$ & $3.15(2.278)$ & $3.11(2.258)$ & $.360^{\mathrm{a}}$ \\
\hline Hospital stay (days) & $0.74(0.423)$ & $0.65(0.314)$ & $0.66(0.325)$ & $.185^{\mathrm{a}}$ \\
\hline Admission - part of the day (\%) & 6.5 & 2.4 & & $.165^{\mathrm{b}}$ \\
\hline Morning & 4.3 & 3.2 & 2.8 & \\
\hline Afternoon & 37.0 & 28.3 & 3.3 & \\
\hline Evening & 52.2 & 66.1 & 29.1 & \\
\hline Night & & & 64.8 & \\
\hline Drugs (\%) & & & & $.056^{\mathrm{b}}$ \\
\hline Yes & 19.1 & 10.0 & 10.9 & \\
\hline Cannabis & 8.5 & 6.1 & 6.3 & \\
\hline Cocaine & 2.1 & 0.7 & 0.8 & \\
\hline XTC & 0.0 & 0.4 & 0.4 & \\
\hline GHB & 6.4 & 0.2 & 0.8 & \\
\hline Else & 2.1 & 2.6 & 2.6 & \\
\hline No & 80.9 & 90.0 & 89.1 & \\
\hline
\end{tabular}

${ }^{\mathrm{a}}$ Mann-Whitney $\mathrm{U}$ test; ${ }^{\mathrm{b}} \mathrm{Chi}$-square test.

$\left(\chi^{2}(3, N=509)=5.009, p=.165\right)$ were equal in both groups (Table 3 ).

\section{Habitual characteristics}

No significant difference in habitual characteristics was found: age of consuming first alcoholic beverage $(u=$ 8081.5, $z=-1.061, p=.289)$, smoking $\left(\chi^{2}(1, N=498)\right.$ $=0.198, p=.657)$, and alcohol consumption during the weekend ( $u=6166.0, z=-0.274, p=.784)$ were comparable in both groups (Table 4).

\section{Discussion}

To control for random distribution and equal distribution in both groups (adolescents who consumed energy drinks $[\mathrm{ED}+]$ and adolescents who did not consume energy drinks [ED-]), the baseline characteristics (gender and mean age at admission) for both groups were compared. The baseline characteristics did not differ significantly, which means that both groups were comparable. In an earlier study, a significant difference in ethnicity for the consumption of energy drinks in the Netherlands was observed (Van Dorsselaer et al., 2016). In this study, this difference was significant as well: there were more adolescents with non-Dutch ethnicity in the
ED+ group than in the ED- group. Furthermore, there were significantly more Dutch adolescents with a lower education level who consumed AmED, a trend that was also found in another Dutch study (Van Dorsselaer et al., 2016). These findings confirm that the population in this study is representative of the Dutch adolescent population.

This study examined the relation between BAC and AmED consumption for the first time; except for a small case series, no other research has been performed (Cleary et al., 2012). No significant difference in BAC between both groups (ED+ and ED-) was found, in contrast to expectations. Common sense might lead to the expectation that youngsters who consume energy drinks have more energy and therefore a longer drinking event, which causes higher BAC. However, this seems to not be the case; possibly further qualitative research should investigate this mechanism in-depth. These qualitative studies could, for instance, consist of drinking events, analyses after excessive drinking (time, number of drinks, BAC), interviews, focus group sessions, or critical incident approach studies with the target audiences. Hospital stay and duration of reduced consciousness were comparable in both groups. Because adolescents who consume energy drinks stay awake longer, consumption of AmED might lead to admission at

Table 4. Habitual Characteristics.

\begin{tabular}{|c|c|c|c|c|}
\hline & $E D+(N=48)(S D)$ & $\mathrm{ED}-(N=475)(S D)$ & Total $(N=523)$ & $p$-value \\
\hline Age of first alcoholic beverage (years) & 14.67 (1.128) & $14.43(1.304)$ & 14.45 (1.288) & $.289^{\mathrm{a}}$ \\
\hline Smoking (\%) & & & & $.657^{\mathrm{b}}$ \\
\hline Yes & 14.6 & 17.1 & 16.9 & \\
\hline No & 85.4 & 82.9 & 83.1 & \\
\hline Alcohol consumption during weekend & $1.97(3.251)$ & $1.79(2.993)$ & $1.81(3.016)$ & $.784^{\mathrm{a}}$ \\
\hline
\end{tabular}

${ }^{\mathrm{a}}$ Mann-Whitney U test; ${ }^{\mathrm{b}}$ chi-square test. 
a later time (Koivusilta et al., 2016). In this study, only the part of the day (morning, afternoon, evening, night) was used as a scale. No significant difference was found in the part of the day at admission between the groups. Because the exact time of admission is unknown, it cannot be said whether adolescents who consumed AmED presented at a later time than adolescents who consumed alcohol only.

It is known that AmED consumption leads to drug use and heavier drinking (Marczinski et al., 2013; Martz et al., 2015; O'Brien et al., 2008; Rossheim et al., 2016; Verster et al., 2015; Trapp et al., 2014). Adolescents who consumed AmED used drugs at the time of admission more often than adolescents who consumed alcohol only. Although this difference was only marginally significant $(p=.056)$, adolescents in the ED+ group used drugs almost twice as often (19.1\%) compared to adolescents in the ED- group (10\%). Specifically, cocaine $(2.1 \%$ versus $0.7 \%)$ and $\mathrm{GHB}(6.4 \%$ versus $0.2 \%)$ were used more often in the ED+ group than in the ED- group. Both cocaine and GHB are illicit drugs in the Netherlands (Overheid.nl, 2017). Cocaine and GHB both have various dangerous effects; negative effects of cocaine include hyperthermia, cardiac arrhythmias and cardiac infarctions, cerebrovascular accidents, and hypertension (Goldstein, DesLauriers, \& Burda, 2009). GHB can cause short-term anterograde amnesia, sleepiness, drowsiness, coma, bradycardia, and respiratory depression (Schep, Knudsen, Slaughter, Allister Vale, \& Mégarbane, 2012). The combination of these drugs with alcohol is even more concerning. This combination has negative effects on both physical and mental health. The effects of drugs such as amphetamines and cocaine are enhanced by alcohol, and alcohol reduces some negative effects, such as jitteriness (Marshall, 2006). In the Netherlands, drugs are used more often by adolescents with lower education (Van Dorsselaer et al., 2016). In this study, adolescents with lower education consumed AmED more often. Therefore, education level might be a confounding factor. This issue could be verified by controlling for education level. However, after this variable was controlled for, the subgroups were too small, so no valid conclusions could be drawn. Further large-scale quantitative studies should investigate this issue in more depth. Because the youngsters who end up in the hospital are not a very big group, future studies could explore youth behavior in an earlier phase of the drinking event (e.g., just during nights out).

AmED consumption leads to risk-taking behaviors (sexual risks, injury, need for medical treatment, and riding with an intoxicated driver); however, these specific risks could not be subtracted from the database used (Martz et al., 2015; O’Brien et al., 2008). Instead, differences in risk-taking behavior were tested by evaluating age of consuming first alcoholic beverage, smoking, and alcohol consumption during the weekend. Adolescents who consumed AmED did not consume alcohol more often during the weekend compared to adolescents who consumed alcohol alone. However, in this study, no data were available for alcohol consumption later in life. No differences were observed in the age of consuming first alcoholic beverage and smoking.

In the Netherlands, the quantity of caffeine in energy drinks is approximately $320 \mathrm{mg} / \mathrm{L}$, which is slightly lower than the maximum permitted quantity of caffeine in the Netherlands: 350 mg/L (Voedingscentrum, 2017). Various Nordic countries have maximum permitted quantities that are even lower than that in the Netherlands (Table 5; Meltzer et al., 2008; Thomson \& Schiess, 2010). Energy drinks in other countries, such as the United States (Caffeine Informer, 2017), Australia, and New Zealand (Australian Government, 2015; Thomson \& Schiess, 2010), contain much more caffeine (Table 5).

In addition to caffeine, energy drinks also contain taurine, vitamins, sugar, and sweeteners. Furthermore, they contain guarana, yerba mate, cocoa, and kola nut, which all contain additional amounts of caffeine. The amount of additional caffeine is not mentioned on the can, so the total amount of caffeine may be even higher than listed (Seifert et al., 2011). Earlier studies show there is a doseresponse effect in the consumption of energy drinks and thus in the amount of caffeine taken; consumption of higher quantities of energy drinks leads to more negative effects, such as headache, late bedtime, and sleeping disorders (Koivusilta et al., 2016; Kristjansson et al., 2014).

It is thought that the co-consumption of energy drinks and alcohol masks the subjective intoxication.

Table 5. Caffeine Content in Various Countries.

\begin{tabular}{lcc}
\hline Country & $\begin{array}{c}\text { Maximum Caffeine } \\
\text { Content }\end{array}$ & $\begin{array}{c}\text { Caffeine } \\
\text { Content }\end{array}$ \\
\hline $\begin{array}{l}\text { Netherlands } \\
\text { (Voedingscentrum, 2017) }\end{array}$ & $350 \mathrm{mg} / \mathrm{L}$ & $\sim 320 \mathrm{mg} / \mathrm{L}$ \\
$\begin{array}{l}\text { United States (Caffeine } \\
\text { Informer, 2017) }\end{array}$ & No maximum & $64.3-6147 \mathrm{mg} / \mathrm{L}$ \\
$\begin{array}{c}\text { Australia \& New Zealand } \\
\text { (Australian Government, }\end{array}$ & $145-320 \mathrm{mg} / \mathrm{L}^{\mathrm{a}}$ & $145-320 \mathrm{mg} / \mathrm{L}^{\mathrm{a}}$ \\
$\quad$ 2015; Thomson \& Schiess, & & \\
2010) & & \\
$\begin{array}{l}\text { United Kingdom (Food } \\
\text { Standards Agency United }\end{array}$ & No maximum & $320-2667 \mathrm{mg} / \mathrm{L}$ \\
$\quad$ Kingdom, 2017) & & \\
$\begin{array}{l}\text { Finland (Meltzer et al., 2008; } \\
\text { Thomson \& Schiess, 2010) }\end{array}$ & No maximum & $\sim 320 \mathrm{mg} / \mathrm{L}$ \\
$\begin{array}{l}\text { Norway, Denmark, Iceland, } \\
\text { Sweden(Meltzer et al., }\end{array}$ & $150 \mathrm{mg} / \mathrm{L}$ & Up to $150 \mathrm{mg} / \mathrm{L}$ \\
$\quad$ 2008) & & \\
\hline
\end{tabular}

a In Australia and New Zealand, energy shots are sold as dietary supplements. There is no maximum caffeine content for these supplements. Caffeine content in these shots can be as high as $4200 \mathrm{mg} / \mathrm{L}$. 
Alcohol and caffeine have opposite effects on adenosine and dopamine. Normally, during a drinking episode, adenosine activity rises, which has sedative effects. These effects can be inhibited by caffeine. Adenosine inhibits dopamine activity, but because caffeine inhibits adenosine activation, dopamine activation is no longer inhibited. This effect leads to increased reward experience from alcohol and thus more alcohol consumption (Marczinski, 2014). However, a meta-analysis from 2014 showed that there was no significant difference in subjective intoxication after consuming alcohol alone or AmED (Benson, Verster, Alford, \& Scholey, 2014). But when consuming high doses of caffeine $(5.0 \mathrm{mg} / \mathrm{kg}$ for females and $5.5 \mathrm{mg} / \mathrm{kg}$ for males), a significant difference in subjective intoxication is seen (Heinz, de Wit, Lilje, \& Koivusilta, 2013).

Because energy drinks in other countries, such as the United States, Australia, and New Zealand, often contain more caffeine than energy drinks in the Netherlands, the existence of dose-response relations between caffeine and its negative effects and the effect of high doses of caffeine on subjective intoxication and consumption of energy drinks with high caffeine content might have additional, worse effects on BAC and risk-taking behavior (i.e., smoking or alcohol consumption during the weekend) than that seen in this study, in which the hypothesis was mostly based on American literature. Significant differences in these parameters might be seen between adolescents consuming energy drinks with high doses of caffeine and adolescents who consume alcohol only.

\section{Limitations}

The population size in the ED+ group was relatively small. Energy drink consumption was not registered in all adolescents (approximately 55\% in 2015 and 2016). This proportion might be the effect of underestimation of the negative effects of AmED among pediatricians. In the Netherlands, drugs are more often used by adolescents with lower education (Van Dorsselaer et al., 2016). In this study, adolescents with lower education consumed AmED more often. It cannot be said whether education level is a confounding factor because the subgroups were too small to draw valid conclusions. It might be useful to collect more data, so correction for education level could be performed.

\section{Conclusions}

There was no significant difference in BAC between adolescents who consumed energy drinks at admission and adolescents who did not. Although the direct clinical health effects such as BAC were comparable in both groups, the consumption of AmED was concerning: adolescents who consumed energy drinks used drugs at the time of admission almost twice as often as adolescents who consumed alcohol only. However, drugs are used more often by adolescents with lower education levels. In the ED+ group, there were significantly more adolescents with lower education levels. This variable might be a confounding factor, but due to very small subgroups, it was impossible to control for education level. The examination of the negative effects of illicit drug use was not in the scope of this study, but pediatricians should be aware of this issue.

Because the direct clinical health effects of energy drinks with higher quantities of caffeine are unknown, more research is needed. Consumption of these energy drinks in combination with alcohol might lead to direct negative clinical health effects, such as higher BAC. Therefore, the maximum permitted quantity of caffeine in the Netherlands should not be raised, and in other countries, such as the United States, a maximum permitted quantity should be introduced.

\section{Acknowledgments}

We would like to thank the Dutch Pediatric Surveillance System (NSCK) for the completion of the NSCK database and all the pediatricians who completed the questionnaire.

\section{References}

Arria, A. M., Caldeira, K. M., Kasperski, S. J., Vincents, K. B., Griffiths, R. R., \& O’Grady, K. E. (2011). Energy drink consumption and increased risk for alcohol dependence. Alcoholism: Clinical and Experimental Research, 35, 365-375. doi:10.1111/j.1530-0277.2010.01352.x

Australian Government. (2015). Australia New Zealand Food Standards Code: Standard 2.6.4-Formulated caffeinated beverages. Retrieved from https://www.legislation.gov.au/ Details/F2015L00467

Benson, S., Verster, J. C., Alford, C., \& Scholey, A. (2014). Effects of mixing alcohol with caffeinated beverages on subjective intoxication: A systematic review and meta-analysis. Neuroscience and Biobehavioral Reviews, 47, 16-21. doi:10.1016/j.neubiorev.2014.07.008

Bonar, E. E., Cunningham, R. M., Polshkova, S., Chermack, S. T., Blow, F. C., \& Walton, M. A. (2015). Alcohol and energy drink use among adolescents seeking emergency department care. Addictive Behaviors, 45, 11-17. doi:10.1016/j. addbeh.2014.11.023

Bonomo, Y., Coffey, C., Wolfe, R., Lynskey, M., Bowes, G., \& Patton, G. (2001). Adverse outcomes of alcohol use in adolescents. Addiction, 96, 1485-1496. doi:10.1046/j.13600443.2001.9610148512.x

Bouthoorn, S. H., Van der Ploeg, T., Van Erkel, N. E., \& Van der Lely, N. (2011). Alcohol intoxication among Dutch adolescents: Acute medical complications in the years 2000- 
2010. Clinical Paediatrics, 50, 244-251. doi:10.1177/ 0009922810388509

Caffeine Informer. (2017). Caffeine content of drinks. Retrieved from https://www.caffeineinformer.com/the-caffeine-database

Cleary, K., Levine, D. A., \& Hoffman, R. S. (2012). Adolescents and young adults presenting to the emergency department intoxicated from a caffeinated alcoholic beverage: A case series. Annals of Emergency Medicine, 59, 67-69. doi:10.1016/j.annemergmed.2011.06.015

Corrao, G., Bagnardi, V., Zambon, A., \& La Vecchia, C. (2004). A meta-analysis of alcohol consumption and the risk of 15 diseases. Preventive Medicine, 38, 613-619. doi:10.1016/j. ypmed.2003.11.027

Díaz, A., Treviño, S., Guevara, J., Muños-Arenas, G., Brambila, E., \& Espinosa, B., ... Aguilar-Alonso, P. (2016). Energy drink administration in combination with alcohol causes an inflammatory response and oxidative stress in the hippocampus and temporal lobe. Oxidative Medicine and Cellular Longevity, 2016, 1-9. doi:10.1155/2016/8725354

Emond, J. A., Gilbert-Diamond, D., Tanski, S. E., \& Sargent, J. D. (2014). Energy drink consumption and the risk of alcohol use disorders among a national sample of adolescents and young adults. The Journal of Pediatrics, 165, 11941200. doi:10.1016/j.jpeds.2014.08.050

Ferreira, S. E., Hartmann Quadros, I. M., Trindade, A. A., Takahashi, S., Koyama, R. G., \& Souza-Formigoni, M. L. O. (2004). Can energy drinks reduce the depressor effect of ethanol? An experimental study in mice. Physiology \& Behavior, 82, 841-847. doi:10.1016/S0031-9384(04)00284-7

Food Standards Agency United Kingdom. (2017). High-caffeine energy drinks and other foods containing caffeine. Retrieved from https://www.food.gov.uk/science/additives/ energydrinks

Goldstein, R. A., DesLauriers, C., \& Burda, A. M. (2009). Cocaine: History, social implications, and toxicity-A review. Disease- $a$ Month, 55, 6-38. doi:10.1016/j.disamonth.2008.10.002

Gore, F. M., Bloem, P. J. N., Patton, G. C., Ferguson, J., Coffey, C., ... Mathers, C. D. (2011). Global burden of disease in young people aged 10-24 years: A systematic analysis. Lancet, 377, 2093-2102. doi:10.1016/S01406736(11)60512-6

Gross, C., Reis, O., Kraus, L., Piontek, D., Zimmerman, U. S., \& RISCA Group. (2016). Long-term outcomes after adolescent in-patient treatment due to alcohol intoxication: A control group study. Drug and Alcohol Dependence, 162, 116-123. doi:10.1016/j.drugalcdep.2016.02.037

Guerri, C., \& Pascual, M. (2010). Mechanisms involved in the neurotoxic, cognitive, and neurobehavioral effects of alcohol consumption during adolescence. Alcohol, 44, 15-26. doi:10.1016/j.alcohol.2009.10.003

Heinz, A. J., de Wit, H., Lilje, T. C., \& Koivusilta, L. (2013). The combined effects of alcohol, caffeine and expectancies on subjective experience, impulsivity and risk-taking. Experimental and Clinical Psychopharmacology, 21, 222-234. doi:10.1037/a0032337

Koivusilta, L., Kuoppamäki, H., \& Rimpelä, A. (2016). Energy drink consumption, health complaints and late bedtime among young adolescents. International Journal of Public Health, 61, 299-306. doi:10.1007/s00038-016-0797-9

Kristjansson, A. L., Sigfusdottir, I. D., Mann, M. J., \& James, J. E. (2014). Caffeinated sugar-sweetened beverages and common physical complaints in Icelandic children aged
10-12 years. Preventive Medicine, 58, 40-44. doi:10.1016/j. ypmed.2013.10.011

Magnezi, R., Bergman, L. C., Grinvald-Fogel, H., \& Cohen, H. A. (2015). A survey of energy drink and alcohol mixed with energy drink consumption. Israel Journal of Health Policy Research, 55, 1-8. doi:10.1186/s13584-015-0052-5

Marczinski, C. A. (2014). Combined alcohol and energy drink use: Hedonistic motives, adenosine, and alcohol dependence. Alcoholism: Clinical and Experimental Research, 38, 1822-1825. doi:10.1111/acer.12493

Marczinski, C. A., Fillmore, M. T., Henges, A. L., Ramsey, M. A., \& Young, C. R. (2013). Mixing an energy drink with an alcoholic beverage increases motivation for more alcohol in college students. Alcoholism: Clinical and Experimental Research, 37, 276-283. doi:10.1111/j.1530-0277.2012.01868.x

Marshall, E. J. (2006). Multiple substance use. Psychiatry, 5, 461-463. doi:10.1053/j.mppsy.2006.09.005

Martz, M. E., Patrick, M. E., \& Schulenberg, J. E. (2015). Alcohol mixed with energy drink use among U.S. 12th-grade students: Prevalence, correlates, and associations with unsafe driving. Journal of Adolescent Health, 46, 557-563. doi:10.1016/j.jadohealth.2015.01.019

Mattson, M. E. (2013). Update on emergency department visits involving energy drinks: A continuing public health concern. Center for Behavioral Health Statistics and Quality Report. Rockville, MD: Substance Abuse and Mental Health Services Administration.

Meltzer, H. M., Fotland, T. O., Alexander, J., Elind, E., Hallström, H., Lam, H. R., ... Solbergsdottir, E. (2008). Risk assessment of caffeine among children and adolescents in the Nordic countries (Rep. No. 551). Copenhagen: Nordic Council of Ministers.

Miyake, E. R., \& Marmorstein, N. R. (2015). Energy drink consumption and later alcohol use among early adolescents. Addictive Behaviors, 43, 60-65. doi:10.1016/j.addbeh.2014.12.009

O'Brien, M. C., McCoy, T. P., Rhodes, S. D., Wagoner, A., \& Wolfson, M. (2008). Caffeinated cocktails: Energy drink consumption, high-risk drinking, and alcohol-related consequences among college students. Academic Emergency Medicine, 15, 453-460. doi:10.1111/j.1553-2712.2008.00085.x

Overheid.nl. (2017). Opiumwet-Lijst 1. Retrieved from http:// wetten.overheid.nl/BWBR0001941/2016-08-01\#BijlageI

Patrick, M. E., Evans-Polce, R. J., \& Maggs, J. L. (2014). Use of alcohol mixed with energy drinks as a predictor of alcoholrelated consequences two years later. Journal of Studies on Alcohol and Drugs, 75, 753-757. doi:10.15288/jsad.2014.75.753

Red Bull. (2017). Red Bull energy drink. Retrieved from http:// energydrink.redbull.com/company

Reissig, C. J., Strain, E. C., \& Griffiths, R. R. (2009). Caffeinated energy drinks: A growing problem. Drug and Alcohol Dependence, 99, 1-10. doi:10.1016/j. drugalcdep.2008.08.001

Riesselmann, B., Rosenbaum, F., \& Schneider, V. (1998). Alcohol and energy drink: Can combined consumption of both beverages modify automobile driving fitness? Blutalkohol, 33, 201-208.

Roemer, A., \& Stockwell, T. (2017). Alcohol mixed with energy drinks and risk of injury: A systematic review. Journal of Studies on Alcohol and Drugs, 78, 175-183. doi:10.15288/ jsad.2017.78.175

Rossheim, M. E., Thombs, D. L., Weiler, R. M., Barry, A. E., Suzuki, S., Walters, S. T., ... Cannell, B. (2016). Alcohol 
mixed with energy drink: Use may be a consequence of heavy drinking. Addictive Behaviors, 57, 55-61. doi:10.1016/j.addbeh.2016.02.013

Schep, L. J., Knudsen, K., Slaughter, R. J., Allister Vale, J., \& Mégarbane, B. (2012). The clinical toxicology of gammahydroxybutyrate, gamma-butyrolactone and 1,4-butanediol. Clinical Toxicology, 50, 458-470. doi:10.3109/ 15563650.2012 .702218

Seifert, S. M., Schaechter, J. L., Hershorin, E. R., \& Lipshultz, S. E. (2011). Health effects of energy drinks on children, adolescents, and young adults. Peadiatrics, 127, 511-528. doi:10.1542/peds.2009-3592

Skewes, M. C., Decou, C. R., \& Gonzales, V. M. (2013). Energy drink use, problem drinking and drinking motives in a diverse sample of Alaskan college students. International Journal of Circumpolar Health, 72, 21204. doi:10.3402/ijch. v72i0.21204

Thomson, B., \& Schiess, S. (2010). Risk profile: Caffeine in energy drinks and energy shots. Christchurch, New Zealand: Institute of Environmental Science \& Research Limited.

Trapp, G. S. A., Allen, K. L., O’Sullivan, T., Robinson, M., Jacoby, P., \& Oddy, W. H. (2014). Energy drink consumption among young Australian adults: Associations with alcohol and illicit drug use. Drug and Alcohol Dependence, 134, 30-37. doi:10.1016/j.drugalcdep.2013.09.006

U.S. Food and Drug Administration. (2010). Update on caffeinated alcoholic beverages. Retrieved from http://wayback. archiveit.org/7993/20170723105409/https://www.fda.gov/ NewsEvents/PublicHealthFocus/ucm234900.htm van der Lely, N. (2016). Alcohol and adolescents: A bad combination. Praktische Pediatrie, 1, 15-19.

Van der Lely, N., Schreurs, C., Van Hoof, J. J., \& Van Dalen, W. E. (2016). Hospitalizations due to alcohol and alcohol intoxication in Dutch adolescents from 2007 to 2015. NSCK, Reinier de Graaf Groep, Universiteit Twente, Nederlands Instituut voor Alcohol beleid STAP. http://www.stap. $\mathrm{nl} / \mathrm{nl} /$ publicaties/factsheets.html/3522/4720/factsheetalcoho lopnames-en-alcoholintoxicaties-bij-minderjarigen-van2007-tot-en-met-2015

Van Dorsselaer, S., Tuithof, M., Verdurmen, J., Spit, M., Van Laar, M., \& Monshouwer, K. (2016). Jeugd en riskantgedrag 2015. Utrecht, Netherlands: Trimbosinstituut.

Verster, J. C., Benson, S., Johnson, S. J., Scholey, A., \& Alford, C. (2015). Mixing alcohol with energy drink (AMED) and total alcohol consumption: A systematic review and meta-analysis. Human Psychopharmacology: Clinical and Experimental, 31, 2-10. doi:10.1002/ hup. 2513

Voedingscentrum. (2017). Energiedrankjes. Retrieved from http://www.voedingscentrum.nl/encyclopedie/energiedrankjes. aspx

Woolsey, C. L., Williams, R. D., Housman, J. M., Barry, A. E., Jacobson, B. H., \& Evans, M. W. (2015). Combined use of alcohol and energy drinks increases participation in high-risk drinking and driving behaviors among college students. Journal of Studies on Alcohol and Drugs, 76, 615-619. doi:10.15288/jsad.2015.76.615 